\title{
Cinacalcet use in pediatric chronic kidney disease
}

\author{
A survey study
}

Rafif A. Al-Ahmed, MD, Areej A. Sheerah, MD, Khalid A. Alhasan, MD, Jameela A. Kari, FRCPCH.

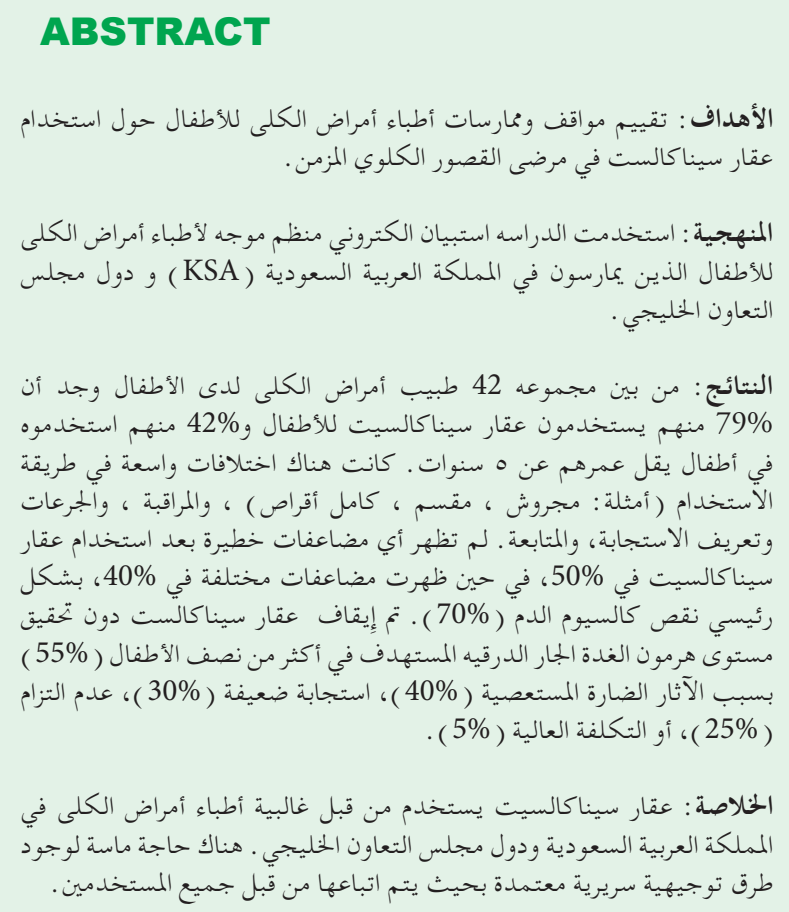

Objectives: To evaluate the practice and attitude of pediatrics nephrologists about cinacalcet use in children.

Methods: An electronic structured questionnaire was answered by pediatric nephrologists practicing in the Kingdom of Saudi Arabia (KSA) and Gulf Council countries (GCC).

Results: A total of 42 pediatric nephrologists responded, of them, $42 \%$ used cinacalcet for young children $\leq 5$ years of age and $79 \%$ used for children. There were wide variations in the method of administration (examples: crushed, divided, whole tablets), monitoring, doses and response definition, and follow-up. No serious complications after starting cinacalcet was observed in 50\%, while $40 \%$ reported various complications, mainly hypocalcemia (70\%).
Cinacalcet was stopped without achieving the target parathyroid hormone in more than half $(55 \%)$ of children because of intractable adverse effects $(40 \%)$, poor response $(30 \%)$, non-adherence $(25 \%)$, or high cost $(5 \%)$.

Conclusion: Cinacalcet is used by the majority of pediatric nephrologists in KSA and GCC. A standard clinical guideline is needed to be followed by all users.

Keywords: cincacalcet, chronic kidney disease, children

Saudi Med J 2020; Vol. 41 (5): 479-484 doi: 10.15537/smj.2020.5.25072

From the Paediatric Nephrology Center of Excellence, Department of Pediatrics (Al-Ahmed, Sheerah, Kari); from the Pediatrics Department (Kari), King Abdulaziz University, Jeddah; and from the Pediatric Department (Alhasan), College of Medicine, King Saud University, Riyadh, Kingdom of Saudi Arabia.

Received 23rd December 2019. Accepted 4th July 2020.

Address correspondence and reprint request to: Dr. Rafif A. Al-Ahmed, Department of Pediatrics, King Abdulaziz University, Jeddah, Kingdom of Saudi Arabia.E-mail: rafifali33@gmail.com

ORCID ID: https://orcid.org/0000-0003-2926-9604

Secondary hyperparathyroidism (SHPT) is associated $\checkmark$ with chronic kidney disease (CKD) and contributes to the occurrence of mineral and bone disorder (MBD). ${ }^{1,2}$ The management of CKD-MBD includes limiting dietary phosphate intake and adding phosphate binders in order to normalize serum phosphorus levels. Optimization of the intact parathyroid hormone (iPTH) level, could be achieved by medical therapy, such as calcitriol, vitamin D analogs, and calcimimetics. ${ }^{3}$

Patients with advanced CKD tend to have underexpression of vitamin D receptor (VDR), and calciumsensing receptor (CaSR), leading to poor response of parathyroid cells to calcium or calcitriol, which leads to parathyroid hyperplasia. ${ }^{4}$ 
Calcimimetics are designed to treat SHPT as they lead to a reduction in circulating PTH levels through increased sensitivity to extracellular calcium. ${ }^{5}$ Cinacalcet is used as calcimimetic in adult patients with end-stage kidney disease (ESKD), receiving dialysis. ${ }^{5}$ It has also been shown to reduce fibroblast growth factor-23 (FGF-23), the calcium-phosphorous ion product, serum calcium, phosphorus in adult patients treated with maintenance dialysis. ${ }^{6}$ Furthermore, it may help in stopping the process of vascular calcifications and in reducing FGF-23 levels. ${ }^{6}$

Cinacalcet was shown to reduce the need for parathyroidectomy in adult patients with ESKD. ${ }^{7,8}$ The Kidney Disease Improving Global Outcomes (KDIGO) clinical practice guideline update on CKD-MBD suggests the use of calcimimetics in patients with ESKD receiving dialysis and suffering from SHPT. ${ }^{9}$ However, calcimimetics are not yet approved for pediatric use in United States (US) or in the Kingdom of Saudi Arabia (KSA) because there is insufficient evidence for its safety and efficacy in children. The European Medicines Agency (EMA) approved the use of cinacalcet for the treatment of SHPT in children aged above 3 years on dialysis in whom SHPT is not adequately controlled with standard therapy. ${ }^{10}$

Initial reports on its use in children have been limited to case reports or single-center, small, observational studies. ${ }^{11-14}$ Recently, a multicenter, prospective, doubleblind, placebo-controlled study showed that cinacalcet is effective and safe in children with SHPT on dialysis. ${ }^{15}$

In this study, we evaluate the practice and attitude of using cinacalcet in children with $\mathrm{CKD}$ among pediatric nephrologists working in Gulf Council countries (GCC).

Methods. This is a cross sectional survey conducted in the KSA, organized by King Abdulaziz University Hospital (KAUH), Jeddah, KSA over 3 months (April to June 2019). A structured questionnaire regarding the clinical practice of using cinacalcet in pediatric patients with ESKD was answered by pediatric nephrologists in the KSA and GCC. We included only qualified pediatric nephrology consultants and excluded specialists and doctors in training

The questionnaire included questions on what is considered an indication for cinacalcet use, dosage

Disclosure. Authors have no conflict of interests, and the work was not supported or funded by any drug company. used, frequency, follow-up laboratories and observed side effects (Table 1). It also contains questions regarding the practice of nephrologists when treating patients with CKD-MBD, including type of phosphate binders typically used and the prevalence of uncontrolled CKD-MBD in their centers. The research and ethics committee of KAUH has approved the study. All nephrologists provided informed consent prior to completing the surveys. The link to the survey is found here: https://docs.google.com/file/d/1PNXrNYjGh Nz43aM0zt7OQg0oax3Q_9EU/edit?usp=docslist_ api\&filetype $=$ msword

Statistical analysis. Statistical analysis was performed using the Statistical Package of Social Science Statistics for Windows, version 26 (IBM Corp, Armonk, NY, USA). Statistical methods were designed with guidance from a biomedical statistician.

Results. There were 42 responses from 82 pediatric nephrologists who received the survey (52\%), mainly from the KSA (80\%) (Table 1). Those from the KSA were mainly from Riyadh (50\%) and Makkah regions $(30 \%)$. Most of the respondents (66\%) had more than 30 children with CKD who were followed up in their clinics; notably, $40 \%$ had more than 50 children with CKD under their care (Table 1). Approximately, 93\% of the responders had the facilities to provide peritoneal dialysis at their centers. In addition, $80 \%$ had the service of hemodialysis while only $54 \%$ work in renal transplantation centers.

Chronic kidney diseas-MBD was reported as very common by the majority. Also, calcium-based phosphate binders are used by all responders while non-calcium-containing phosphate binders was used by most responders (Table 1). Two pediatric nephrologists $(4.8 \%)$ reported using aluminum-based phosphate binders and 7 pediatric nephrologists (16.7\%) reported using aluminum-based phosphate. Use of calcimimetics like cinacalcet were reported by $79 \%$ of the respondents. Most of the respondents used cinacalcet in children less than 5 years old $(57.6 \%)$ while $36.4 \%$ reported using it in 5-15 years old children with CKD.

None of the respondents used calcimimetics as the first line to treat SHPT; however, it was used as second agent for cases of refractory hyperparathyroidism or for cases of hyperparathyroidism with hypercalcemia (Table 1). Two-thirds of nephrologists considered the iPTH level of $300 \mathrm{pg} / \mathrm{ml}$ (30 pmol/L) as alarming to start cinacalcet while one-third considered the level of $150-300 \mathrm{pg} / \mathrm{ml}(15-30 \mathrm{pmol} / \mathrm{L})$ as sufficiently high. A majority $(44 \%)$ would notstart cinacalcet before reaching the maximum dose of active vitamin $\mathrm{D}(2 \mathrm{mcg} / \mathrm{day})$ 
Table 1 - Summary of the questionnaire results.

\begin{tabular}{|c|c|c|c|c|}
\hline \multirow{2}{*}{$\begin{array}{l}\text { Questions } \\
\text { Number of responses } n=42\end{array}$} & \multicolumn{4}{|c|}{ Responses } \\
\hline & KSA $(80 \%)$ & Arab countries $(20 \%)$ & & \\
\hline No. of children with CKD followed & $66 \%>30$ children & $40 \%>50$ children & & \\
\hline Prevalence of CKD-MBD & $45 \%$ very common & $43 \%$ less common & $12 \%$ very rare & \\
\hline Type of phosphate binders & $\begin{array}{l}97 \% \text { calcium based } \\
\text { phosphate binders }\end{array}$ & $79 \%$ non-calcium containing phosphate & $\begin{array}{l}4.8 \% \text { aluminum- } \\
\text { based }\end{array}$ & \\
\hline Used cinacalcet for CKD MBD patients & $79 \%$ yes & $21 \%$ no & & \\
\hline $\begin{array}{l}\text { Number of patients who received } \\
\text { cinacalcet }\end{array}$ & $\begin{array}{l}57.6 \% \text { less than } 5 \\
\text { patient }\end{array}$ & $36.4 \%$ in 5 to 15 patients & & \\
\hline Age of starting cinacalcet & $\begin{array}{l}43 \% \text { less than } 5 \text { years } \\
\text { of age }\end{array}$ & $57 \%$ more than 5 years of age & & \\
\hline Indication of use cinacalcet & $\begin{array}{l}9 \% \text { second agent for } \\
\text { SHPT }\end{array}$ & $48.5 \%$ refractory hyperparathyroidism & $\begin{array}{l}39 \% \\
\text { hyperparathyroidism } \\
\text { with hypercalcemia }\end{array}$ & \\
\hline Level of iPTH to start cinacalcet & $\begin{array}{l}64 \%>300 \mathrm{pg} / \mathrm{ml} \\
(30 \mathrm{pmol} / \mathrm{l})\end{array}$ & $36 \% 150-300 \mathrm{pg} / \mathrm{ml}(15-30 \mathrm{Pmol} / \mathrm{L})$ & & \\
\hline Daily dose of cinacalcet & $\begin{array}{l}45.5 \%, \\
0.5 \text { to } 2 \mathrm{mg} / \mathrm{kg}\end{array}$ & $15 \%, 15 \mathrm{mg}$ & $27 \% 30 \mathrm{mg}$ & $\begin{array}{l}12 \% 30 \mathrm{mg} \\
\mathrm{EOD}\end{array}$ \\
\hline Method of administration & $70 \%$ whole tablet & $15 \%$ crushed tablets & $15 \%$ divided tablets & \\
\hline Relation to food & $81 \%$ no instruction & $9 \%$ with meals & $9 \%$ after meals & \\
\hline $\begin{array}{l}\text { Timing of cinacalcet in relation with } \\
\text { dialysis }\end{array}$ & $70 \%$ no instruction & $25 \%$ after dialysis & $5 \%$ before the dialysis & \\
\hline $\begin{array}{l}\text { Baseline investigations performed before } \\
\text { cinacalcet }\end{array}$ & $100 \%$ iPTH level & $97 \%$ serum calcium & $88 \%$ serum phosphate & $\begin{array}{l}66 \% \\
\text { vitamin D3 }\end{array}$ \\
\hline iPTH level monitoring after cinacalcet & $73 \%$ monthly & $15 \%$ weekly & $12 \%$ every 3 months & \\
\hline Timing of the first iPTH level & $20 \%$ after one week & $16 \%$ after 2 weeks & $50 \%$ after one month & $\begin{array}{l}4 \% \text { after } 3 \\
\text { month }\end{array}$ \\
\hline $\begin{array}{l}\text { Follow-up calcium level after } \\
\text { commencing cinacalcet }\end{array}$ & $61 \%$ weekly & $27 \%$ daily & $12 \%$ every 12 hours & \\
\hline Complications after starting cinacalcet & $\begin{array}{l}50 \% \text { no serious } \\
\text { complications }\end{array}$ & $\begin{array}{l}40 \% \text { complications of hypocalcemia } \\
(70 \%) \text {, GI complications }(25 \%) \text {, } \\
\text { adynamic bone disease }(11 \%) \text { and } \\
\text { seizures }(4 \%)\end{array}$ & $10 \%$ not sure & \\
\hline $\begin{array}{l}\text { Reason to stop cinacalcet without } \\
\text { achieving the target iPTH }\end{array}$ & $\begin{array}{l}40 \% \text { intractable side } \\
\text { effects }\end{array}$ & $30 \%$ poor response & $25 \%$ poor compliance & $5 \%$ cost \\
\hline Success of cinacalcet was defined as & $\begin{array}{l}61 \% \text { to a } 50 \% \\
\text { reduction in iPTH } \\
\text { level }\end{array}$ & $30 \%$ to a $25 \%$ reduction in iPTH level & $9 \%$ normal iPTH & \\
\hline $\begin{array}{l}\text { Indication of surgical parathyroidectomy } \\
\text { in the previous } 5 \text { years }\end{array}$ & $\begin{array}{l}94 \% \text { failure to } \\
\text { respond to cinacalcet }\end{array}$ & $6 \%$ side effect of cinacalcet & & \\
\hline $\begin{array}{l}\text { Use cinacalcet to improve the outcome } \\
\text { of childhood CKD-MBD. }\end{array}$ & $\begin{array}{l}47 \% \text { using cinacalcet } \\
\text { early will improve the } \\
\text { outcome }\end{array}$ & $6 \%$ no benefit & $47 \%$ unsure & \\
\hline $\begin{array}{l}\text { Using cinacalcet as medical } \\
\text { parathyroidectomy }\end{array}$ & $\begin{array}{l}68 \% \text { using } \\
\text { cinacalcet as medical } \\
\text { parathyroidectomy } \\
\text { instead of surgical }\end{array}$ & $\begin{array}{l}10 \% \text { are against cinacalcet as medical } \\
\text { parathyroidectomy }\end{array}$ & $22 \%$ unsure & \\
\hline CKD: chronic kidney & $\begin{array}{l}\text { ease, MBD: mineral bo } \\
\text { SHPT: secondary hyp }\end{array}$ & $\begin{array}{l}\text { diseases, iPTH: intact parathyroid horm } \\
\text { arathyroidism, EOD: every other day }\end{array}$ & , GI: gastrointestinal, & \\
\hline
\end{tabular}


while $41 \%$ considered $1 \mathrm{mcg} /$ day as sufficiently high; in addition, $11 \%$ chose the dose of $0.1 \mathrm{mcq} / \mathrm{kg} /$ day or $0.5 \mathrm{mcq} / \mathrm{kg} /$ day of calcitriol as the maximum dose they would administer before starting cinacalcet.

A majority (77.8\%) considered low serum calcium $(<2.1 \mathrm{mmol} / \mathrm{L})$ as a contraindication to commence cinacalcet while the remaining respondents choose to use it with calcium supplements.

Most of the responders (45.5\%) would start cinacalcet with a daily dose of $0.5-2 \mathrm{mg} / \mathrm{kg}$, while $15 \%$ would use daily dose of $15 \mathrm{mg}, 27 \%$ use daily dose of $30 \mathrm{mg}$, and $12 \%$ use $30 \mathrm{mg}$ every other day. Cinacalcet was administered as a whole tablet by $70 \%$, while $15 \%$ used crushed tablets, and 15\% used divided tablets. Fifty percent of respondents were happy with crushed or divided cinacalcet given to children who cannot swallow a whole tablet. Approximately, $81 \%$ did not provide any instructions regarding timing with meals, while 9\% instructed children to take cinacalcet before meals, and another $9 \%$ instructed patients to take it after meals. Similarly, 70\% did not have concerns regarding the timing of cinacalcet in relation with dialysis, while $25 \%$ advised to administer cinacalcet after dialysis.

Baseline investigations, which are typically performed before providing cinacalcet, included PTH (100\% of respondents), serum calcium $(97 \%)$, serum phosphate (88\%), vitamin D3 level (66\%), alkaline phosphatase (60\%), and serum albumin (50\%). Seventy-three percent would follow the PTH level monthly after beginning cinacalcet, $15 \%$ would do so on a weekly basis and $12 \%$ every 3 months. Similarly, there was a wide variation in the timing of the first PTH level after cinacalcet: $20 \%$ after one week, 16\% after 2 weeks, and $50 \%$ after one month. Approximately, $60 \%$ would follow calcium levels on a weekly basis after starting cinacalcet, $27 \%$ daily, and $12 \%$ every 12 hours.

No serious complications after starting cinacalcet was observed in $50 \%$, while $40 \%$ reported complications. Hypocalcemia was the main adverse effect of $70 \%$, followed by gastrointestinal complications of $25 \%$, then adynamic bone disease (11\%), and convulsions (4\%). Cinacalcet was stopped without achieving the target PTH in more than half $(55 \%)$ of children because of intractable side effects $(40 \%)$, poor response $(30 \%)$, non-adherence to therapy (25\%), or high cost (5\%).

The success was defined as a $50 \%$ reduction in $\mathrm{iPTH}$ level by $61 \%$ of the responders, while $30 \%$ would consider a $25 \%$ reduction in iPTH level as acceptable, and $9 \%$ thought only normal iPTH is considered as successful cinacalcet treatment. All respondents had cases of surgical parathyroidectomy in the last 5 years. It was justified by failure to respond to cinacalcet by the majority of respondents (94\%) and rarely because of the side effects of cinacalcet (6\%). Approximately, 47\% thought that using cinacalcet early will be useful to improve the outcome of childhood CKD-MBD while $5.6 \%$ thought it was of no benefit and $47 \%$ were unsure. Furthermore, 68\% were in favor of using cinacalcet as medical parathyroidectomy instead of surgical parathyroidectomy while $10 \%$ were against cinacalcet as medical parathyroidectomy and the remaining were unsure.

Discussion. We found that the majority (79\%) of pediatric nephrologists practicing in the KSA and other Arab countries were using calcimimetics like cinacalcet in children with ESKD and inadequately controlled SHPT. Calcimimetics such as cinacalcet are not yet approved for pediatric use in US or in KSA. However, it is approved for pediatric use in the Europe with a product labeling note that caution is advised for patients with other risk factors for QT prolongation (congenital long QT syndrome or receiving medicinal products known to cause QT prolongation). Furthermore, while the maintenance dose is being established, serum calcium should be monitored weekly. ${ }^{9}$

In our study, $42 \%$ of pediatric nephrologists used cinecalcet in young children $\leq 5$ years of age. Although the US Food and Drug Administration has approved cinacalcet in adult patients only, the European Medicines Agency recently has approved the use of cinacalcet in children receiving maintenance dialysis, aged 3 years or older with poorly controlled SHPT using standard therapy. ${ }^{10}$

Recently, a multicenter, double blind, prospective, placebo-controlled study showed that cinacalcet is effective and safe in children older than 6 years of age with SHPT on dialysis. ${ }^{15}$ Morales et $\mathrm{al}^{16}$ reported that its use was effective and safe in small children and infants with refractory SHPT in advanced CKD when using a cautious dosing regimen.

Two-thirds of respondents used cinacalcet with a level of SHPT of $300 \mathrm{pg} / \mathrm{ml}(30 \mathrm{pmol} / \mathrm{l})$ while the remaining one-third considered the level 150-300 pg/ml (15-30 $\mathrm{pmol} / \mathrm{l}$ ) as high enough. Warady et $\mathrm{al}^{15}$ considered children with iPTH levels $>300 \mathrm{pg} / \mathrm{mL}$ as eligible to be recruited in their cinacalcet study; Morales et a ${ }^{16}$ considered enrolling only those with iPTH levels $>500$ $\mathrm{pg} / \mathrm{mL}$.

There is wide variation among respondents regarding the starting dose and the method of administration. There is no recommended standard dose for cinacalcet in children. However, it is usually started at daily dose 
of $0.5 \mathrm{mg} / \mathrm{kg}$ and then titrated every 2 weeks up to a maximum daily dose of $1.5 \mathrm{mg} / \mathrm{kg}$ or until the endpoint is achieved. In the multicenter study of Warday et al, ${ }^{15}$ the starting daily dose was $0.2 \mathrm{mg} / \mathrm{kg} 15$; Morales et $\mathrm{al}^{16}$ used the starting dose of 0.4 to $1.1 \mathrm{mg} / \mathrm{kg} /$ day. Cinacalcet should be commenced along with other conventional therapies for CKD, such as alfacalcidol, phosphate binders, and Ca supplements. ${ }^{17}$

The endpoint is defined as achievement of the recommendations of the National Kidney Foundation's Kidney Disease Outcomes Quality Initiative guidelines, namely iPTH $<150$ to $300 \mathrm{pg} / \mathrm{mL}$ in dialysis patients and 70 to $110 \mathrm{pg} / \mathrm{mL}$ in CKD- stage 4 patients, Ca 8.4 to $9.5 \mathrm{mg} / \mathrm{dL}, \mathrm{P} 3.5$ to $5.5 \mathrm{mg} / \mathrm{dL}$, and $\mathrm{Ca}$ * $\mathrm{P}$ product $<55 \mathrm{mg}^{2} / \mathrm{dL}^{2}$. 9 Secondary endpoints include a lowering from baseline in iPTH levels of $>30 \% .^{15}$

Cinacalcet tablets should be administered with food or immediately after a meal. ${ }^{17}$ The drug manufacturing company recommends that tablets always be taken as a whole and not divided. ${ }^{17}$ However, Morales et $\mathrm{a}^{16}$ reported the use of 30-mg tablets which were divided into quarters or halves, pulverized, and diluted with a small volume of water and administered once daily to the child via gastrostomy tube or oral route. ${ }^{16}$ Conversely, in the study of Warady et al, ${ }^{15}$ cinacalcet for oral administration, was prepared as capsules (5 $\mathrm{mg}$ ) and as a syrup (in a sucrose suspension) with matching placebos. Recently the American Society of Health-System Pharmacists, has reported the stability of extemporaneously compounded cinacalcet $5-\mathrm{mg} / \mathrm{mL}$ oral suspensions which is stable for at least 64 days under refrigeration or at room temperature. ${ }^{18}$

There was also wide variation in the practice of follow-up among respondents. iPTH levels should be monitored no earlier than 12 hours after most recent dose. ${ }^{19}$ The recommendation is to titrate the dose every 2 to 4 weeks through sequential increasing doses of once daily as necessary to achieve targeted iPTH levels. ${ }^{19}$

Interestingly, $4.8 \%$ of respondents reported using aluminum-based phosphate binders and 7 pediatric nephrologists $(16.7 \%)$ reported they have used them before. While the majority of respondents used calciumcontaining phosphate binders or sevelamer, the KDIGO guidelines suggest avoiding aluminum-containing binders due to concerns on aluminum toxicity (example: dementia, osteomalacia, anemia). ${ }^{20}$ Furthermore, aluminum seems to absorbed more readily in children than adults, and there are several historic reports of children with kidney failure developing aluminum toxicity from aluminum-containing phosphate binders prior to commencing dialysis. ${ }^{21}$ Aluminum-containing antacids caused a significant aluminum absorption when used in infants, as shown by blood and urine aluminum levels. ${ }^{22}$ Hyperphosphatemia in dialysis patients continues to represent a major challenge, and there is evidence associating serum phosphate concentrations with mortality. ${ }^{23}$

The majority of the respondents used cinacalcet for cases of refractory hyperparathyroidism $(48.5 \%)$, or for cases of hyperparathyroidism with hypercalcemia (39\%). However, a significant percentage of the respondents were using cinacalcet as second agent (9\%). A study showed that cinacalcet is effective in children with SHPT on dialysis, who received standard treatment. ${ }^{15}$ The majority of the respondents (44\%) would not start cinacalcet before reaching the maximum dose of active form of vitamin $\mathrm{D}$ of $2 \mathrm{mcq} /$ day while the remaining considered $1 \mathrm{mcg}$ as a maximum dose. Existing treatment strategies have the potential to elevate serum levels of calcium, which is considered an independent predictor of poor cardiovascular outcomes as a result of metastatic calcification. ${ }^{23}$ The majority $(77.8 \%)$ of nephrologists considered low serum calcium $(<2.1$ $\mathrm{mmol} / \mathrm{L}$ ) as a contraindication to commence cinacalcet while the remaining opted to use calcium supplements with cinacalcet in cases of hypocalcemia. It is widely accepted that hypocalcemia is a contraindication for cinacalcet use. ${ }^{13,15}$

There was also variation in the way the respondents followed-up on children who received cinacalcet. Serum calcium and serum phosphorus should be evaluated within a week while iPTH should be measured within 4 weeks following initiation or dose adjustment of cinacalcet. When the maintenance dose has been achieved, serum calcium and serum phosphorus should be evaluated monthly, and iPTH every 1 to 3 months. ${ }^{23}$ There was a considerable percentage that observed side effects, or had to stop cinacalcet without controlling SHPT. Hypocalcemia, intestinal symptoms, myalgia and chest pain are possible side effects of cinacalcet. Patients with low serum calcium level should not receive cinacalcet. $^{7}$

The current study was conducted with some limitations. The sample of nephrologists surveyed was relatively small and only included those located in the KSA and GCC, which may not make the results of this study generalizable on a global scale. In addition, the validity and reliability of the questionnaire used has not been assessed, and the responses were self-reported, which may affect their accuracy.

In conclusion, cinacalcet is used by the majority of pediatric nephrologists in KSA and GCC. There are wide variations in the indications followed as well as the way it is administered and monitored in children. 
A clinical guidelines needed to be followed by all users. We suggest following the guidelines of the European Society for Pediatric Nephrology regarding cinacalcet use in children, which were recently published. ${ }^{10}$

Acknowledgment. The authors would like to thank Editage (www.editage.com) for English language editing.

\section{References}

1. Cunningham J, Locatelli F, Rodriguez M. Secondary hyperparathyroidism: pathogenesis, disease progression, and therapeutic options. Clin J Am Soc Nephrol 2011; 6: 913-921.

2. El DS, Farag YM, Safdar E, Shalaby MA, Singh AK, Kari JA. Prevalence of hyperparathyroidism, mineral and bone disorders in children with advanced chronic kidney disease. Indian J Pediatr 2016; 83: 420-425.

3. Sanchez CP. Secondary hyperparathyroidism in children with chronic renal failure: pathogenesis and treatment. Paediatr Drugs 2003; 5: 763-776.

4. Torres PA, De BM. Calcium-sensing receptor, calcimimetics, and cardiovascular calcifications in chronic kidney disease. Kidney Int 2012; 82: 19-25.

5. Kawata T, Tokunaga S, Murai M, Masuda N, Haruyama W, Shoukei Y, et al. A novel calcimimetic agent, evocalcet (MT-4580/KHK7580), suppresses the parathyroid cell function with little effect on the gastrointestinal tract or CYP isozymes in vivo and in vitro. PLoS One 2018; 13: e0195316.

6. Wada M, Furuya Y, Sakiyama J, Kobayashi N, Miyata S, Ishii $\mathrm{H}$, et al. The calcimimetic compound NPS R-568 suppresses parathyroid cell proliferation in rats with renal insufficiency. Control of parathyroid cell growth via a calcium receptor. J Clin Invest 1997; 100: 2977-2983.

7. Palmer SC, Nistor I, Craig JC, Pellegrini F, Messa P, Tonelli $\mathrm{M}$, et al. Cinacalcet in patients with chronic kidney disease: a cumulative meta-analysis of randomized controlled trials. PLoS Med 2013; 10: e1001436.

8. Ballinger AE, Palmer SC, Nistor I, Craig JC, Strippoli GF. Calcimimetics for secondary hyperparathyroidism in chronic kidney disease patients. Cochrane Database Syst Rev 2014; 12: CD006254.

9. Kidney Disease: Improving Global Outcomes (KDIGO) CKD-MBD Update Work Group. KDIGO 2017 clinical practice guideline update for the diagnosis, evaluation, prevention, and treatment of chronic kidney disease-mineral and bone disorder (CKD-MBD). Kidney Int Suppl (2011) 2017; 7: 1-59.

10. Bacchetta J, Schmitt CP, Ariceta G, Bakkaloglu SA, Groothoff J, Wan M, et al. Cinacalcet use in paediatric dialysis: a position statement from the European Society for Paediatric Nephrology and the Chronic Kidney Disease-Mineral and Bone Disorders Working Group of the ERA-EDTA. Nephrol Dial Transplant 2020; 35: 47-64.
11. Alharthi AA, Kamal NM, Abukhatwah MW, Sherief LM. Cinacalcet in pediatric and adolescent chronic kidney disease: a single-center experience. Medicine (Baltimore) 2015; 94: e401.

12. Silverstein DM, Kher KK, Moudgil A, Khurana M, Wilcox J, Moylan K. Cinacalcet is efficacious in pediatric dialysis patients. Pediatr Nephrol 2008; 23: 1817-1222.

13. Platt C, Inward C, McGraw M, Dudley J, Tizard J, Burren C, et al. Middle-term use of Cinacalcet in paediatric dialysis patients. Pediatr Nephrol 2010; 25: 143-148.

14. Dotis J, Printza N, Ghogha C, Papachristou F. Short- and middle-term continuous use of cinacalcet in children on peritoneal dialysis. J Pediatr Endocrinol Metab 2013; 26: 39-43.

15. Warady BA, Iles JN, Ariceta G, Dehmel B, Hidalgo G, Jiang X, et al. A randomized, double-blind, placebo-controlled study to assess the efficacy and safety of cinacalcet in pediatric patients with chronic kidney disease and secondary hyperparathyroidism receiving dialysis. Pediatr Nephrol 2019; 34: 475-486.

16. Morales AJ, DeFreitas MJ, Katsoufis CP, Seeherunvong W, Chandar J, Zilleruelo G, et al. Cinacalcet as rescue therapy for refractory hyperparathyroidism in young children with advanced chronic kidney disease. Pediatr Nephrol 2019; 34: 129-135.

17. Cinacalcet hydrochloride tablet, coated. Highlights of prescribing information. [cited 2017]. Available from URL: https://www.accessdata.fda.gov/drugsatfda_docs/ label/2017/021688s023lbl.pdf

18. Thomson K, Hutchinson DJ, Chablani L. Stability of extemporaneously prepared cinacalcet oral suspensions. Am J Health Syst Pharm 2018; 75: e236-e240.

19. Kidney Disease: Improving Global Outcomes (KDIGO) CKD-MBD Work Group. KDIGO clinical practice guideline for the diagnosis, evaluation, prevention, and treatment of Chronic Kidney Disease-Mineral and Bone Disorder (CKD-MBD). Kidney Int Suppl 2009; 113: S1-S130.

20. Foley CM, Polinsky MS, Gruskin AB, Baluarte HJ, Grover WD. Encephalopathy in infants and children with chronic renal disease. Arch Neurol 1981; 38: 656-658.

21. Woodard-Knight L, Fudge A, Teubner J, Simmer K. Aluminium absorption and antacid therapy in infancy. J Paediatr Child Health 1992; 28: 257-259.

22. Block GA, Hulbert-Shearon TE, Levin NW, Port FK. Association of serum phosphorus and calcium $\mathrm{x}$ phosphate product with mortality risk in chronic hemodialysis patients: a national study. Am J Kidney Dis 1998; 31: 607-617.

23. Susantitaphong P, Vadcharavivad S, Susomboon T, Singhan W, Dumrongpisutikul N, Jakchairoongruang $\mathrm{K}$, et al. The effectiveness of cinacalcet: a randomized, open label study in chronic hemodialysis patients with severe secondary hyperparathyroidism. Ren Fail 2019; 41: 326-333. 